\title{
Development of Energy Management System for Residential Load in India
}

\author{
${ }^{* 1}$ Archana Talhar, ${ }^{2}$ Sanjay Bodkhe, ${ }^{3}$ Anjali Chandane \\ ${ }^{* 1,2}$ Department of Electrical Engineering, Shri Ramdeobaba College of Engineering and Management, Nagpur \\ ${ }^{3}$ Department of Electrical Engineering, SKN Sinhgad College of Engineering, Solapur, India \\ Email:archanabelge2@gmail.com,bodkhesb@rknec.edu,anjali.chandane@sknscoe.ac.in
}

\author{
Received: $20^{\text {th }}$ September 2018, Accepted: $11^{\text {th }}$ October 2018, Published: $31^{\text {st }}$ October 2018
}

\begin{abstract}
Electrical power generation scenario is changing across the world dramatically. This is basically due to the fast diminution of conventionally vital sources like coal, oil, natural gas, etc. The alternative solution is renewable energy (RE) sources as they are abundant in nature and freely available. They also help in reducing greenhouse gas emissions. This paper proposes a methodology for integration of RE sources, load scheduling, net metering and real time pricing (RTP) for the residential sector in India. The paper is presenting design, development and testing of an embedded system for a smart home. The proposed system offers and achieves a smart home vitality requirement by mounting sustainable power sources, scheduling and organizing the power flow during peak period, shoulder period and off-peak period. In this process, if excess energy is left, it will be feed to the grid; thereby earning the credits. This method of earning the credits is called net metering. The Global system for mobile communication (GSM) is used for wireless, two-way communication between the proposed system and the user for optimizing the energy consumption and energy bill. A model for the proposed system was designed, implemented and tested by using a controlled load bank to simulate scaled real house consumption pattern and results \& findings were reported.
\end{abstract}

\section{Keywords}

Power Consumption, Renewable Energy, Greenhouse Gas Emissions, Energy Management System, Smart Home, GSM, Real Time Pricing.

\section{Introduction}

The traditional energy resources used for the generation of electricity are decaying day by day and will be gradually vanishing in a couple of years. This has shifted the focus to sustainable energy sources which have the potential to replace fossil fuels, and also reduce $\mathrm{CO}_{2}$ and other dangerous gas emissions. Amongst all renewable energy sources, the solar photovoltaic system is more popular and a promising approach to solve the contradiction around the energy and economic development in the world [1-3]. Some of the developed countries such as United States (US), Germany and Japan have already started energy generation based on RE sources on a large scale. Germany has implemented rooftop PV for one million families. Many families have installed solar photovoltaic power generation to fulfill their own requirement as well as to provide excess power to private "mini power stations", which are capable of supplying an endless stream of electric power to the utility grid [3]. In 2000, the contribution of RE was $0.56 \%$ [7], whereas in 2016, it increased to 5.66\% [7] of total global energy production [4-8]. It is seen that the sustainable energy market had an amazing growth in the past couple of years. As costs are decreasing, wind and solar are becoming more and more popular alternative to fossil fuel. China remains the leading player, but India is progressively moving to the center stage.

The total power generation capacity in India, with reference to region-wise players and the mode by which power is produced; is presented in Table 1. The contribution of sustainable energy production has increased by $24 \%$ in 2016 and will reach to $30 \%$ in 2022 [9]. India is the $3^{\text {rd }}$ largest power producer in the world after China and USA and $7^{\text {th }}$ largest producer of renewable energy in the world [11]. Table 2, presents the region-wise details of the solar power target as mandated by the Ministry of New and Renewable energy, Government of India [10] [12].

Demand Response (DR) is a concept where the customer can temporary make changes in their regular electric consumption patterns to decrease or shift electrical load over time. It permits client involvement in decreasing electricity consumption during the highest pricing hours. The utility company like Commonwealth Edison, Ameren Illinois utilities, Oklahoma Gas \& Electric, Sacramento Municipal Utility and Arizona Public Service are offering these demand response systems to interested customers [12-15].

In India, especially in Maharashtra, the electricity pricing is of slab type. This tariff structure was designed taking into consideration the financially poor class of society. While it provides power at low cost to poor people whose requirement 
of power is less, the existing structure do not extend any encouragement to financially middle and high class customer for energy conservation. Therefore, like many developed countries it is the need of hour that real time pricing should be adopted for this neglected section of the society

\begin{tabular}{|l|l|l|l|l|l|l|l|l|}
\hline \multirow{2}{*}{ Region } & Thermal & \multicolumn{2}{l}{ Total } & Nuclear & Hydro & $\begin{array}{l}\text { Renewable } \\
\text { Energy source }\end{array}$ & Total \\
\cline { 2 - 8 } & Coal & Gas & Diesel & & & & & \\
\hline Northern & 52845.20 & 5781.26 & 0.00 & 58626.46 & 1620.00 & 19653.77 & 13012.88 & 92913.11 \\
\hline Western & 70608.62 & 10806.49 & 0.00 & 81415.11 & 1840.00 & 7547.50 & 20725.38 & 111527.99 \\
\hline Southern & 45782.02 & 6473.66 & 761.58 & 53017.26 & 3320.00 & 11808.03 & 35535.49 & 103680.78 \\
\hline Eastern & 27201.64 & 100.00 & 0.00 & 27301.64 & 0.00 & 4942.12 & 1075.85 & 33319.61 \\
\hline Northeast & 520.02 & 1706.05 & 36.00 & 2262.07 & 0.00 & 1452.00 & 286.46 & 4000.53 \\
\hline Islands & 0.00 & 0.00 & 40.05 & 40.05 & 0.00 & 0.00 & 12.56 & 52.61 \\
\hline All India & $\begin{array}{l}196957.5 \\
0\end{array}$ & 24867.46 & 837.63 & $\begin{array}{l}222662.5 \\
9\end{array}$ & 6780.00 & 45403.42 & 70648.61 & 345494.61 \\
\hline
\end{tabular}

Table 1: Installed Generation Capacity in India (MW) as on $31^{\text {st }}$ July 2018.

\begin{tabular}{|c|l|l|}
\hline Sr. No. & Regions & Solar Power (MW) \\
\hline 1 & Northern Region & 31120 \\
\hline 2 & Western Region & 28410 \\
\hline 3 & Southern Region & 26531 \\
\hline 4 & Eastern Region & 12237 \\
\hline 5 & North Eastern Region & 1205 \\
\hline 6 & Andaman \& Nicobar Islands & 27 \\
\hline 7 & Lakshadweep Islands & 4 \\
\hline & All India & 99533 \\
\hline
\end{tabular}

Table 2: State-wise Solar Power Target to be Achieved by the Year 2022.

This paper proposes a new smart home energy management system (SHEMS) for a residential sector in India considering the integrated approach using grid energy, renewable energy from rooftop PV systems, net metering and an assumed real time pricing structure. A low power level prototype of proposed scheme is designed and fabricated using ATmega 328P microcontroller. A comparative study is carried out to validate the effectiveness of proposed scheme over the conventional system without SHEMS. A GSM is used for wireless, two-way communication between the sources, load and the user for load scheduling and optimization. Section 2 of this paper presents the core idea of the proposed scheme. For validation of proposed system, a low power prototype and its test results are provided in section 3 . The conclusion of the proposed scheme is presented in section 4.

\section{Materials and Methods}

The proposed scheme shown in Fig.1 is based on integration of real time tariff, renewable energy, net metering and load scheduling with the sole objective of reducing electricity bill for middle class. Real time pricing is of many types like day ahead pricing or hourly ahead, time of day, critical peak period and critical peak rebate.

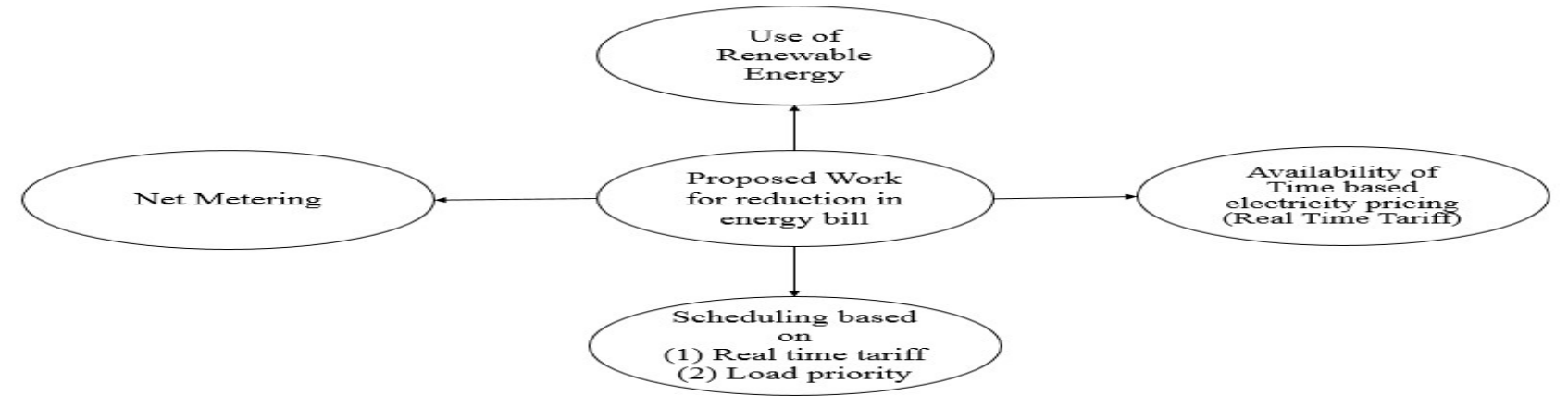

Figure 1: Proposed Scheme for SHEMS

Here in the proposed scheme considering the time of day where the day is split into three time spans and charges are different for each time span. These rates remain fixed day to day over the season. Based upon the real time tariff working in Australia, here assumed certain rates for India to test the effectiveness of proposed system shown in Table 3. In order to 
minimize the cost of electricity, one more parameter is important i.e. scheduling of load which is based on real time tariff and customer preference. Generally, the rates of electricity are high during peak period, medium during shoulder period and low during off peak period. So if the load scheduling is carried out during shoulder and off peak period then it will help consumer to minimize the electricity bill. The load pattern before scheduling and after scheduling is shown in Fig. 2. Blue bar indicates the normal household load pattern, whereas red bar indicates the load pattern after applying scheduling

\begin{tabular}{|l|l|l|c|}
\hline \multicolumn{1}{|c|}{ Mode } & \multicolumn{1}{|c|}{ Time } & \multicolumn{1}{c|}{$\begin{array}{c}\text { Australia } \\
\text { Rate in cent } / \mathrm{kWh}[18]\end{array}$} & $\begin{array}{c}\text { Assumed rate in } \\
\text { India INR/kWh }\end{array}$ \\
\hline Off Peak Period (OPP) & $(10 \mathrm{pm}-7 \mathrm{am})$ & 8.36 cent $/ \mathrm{kWh}$ & $8 \mathrm{INR} / \mathrm{kWh}$ \\
\hline Shoulder Period (SP) & $(7 \mathrm{am}-2 \mathrm{pm} \& 8 \mathrm{pm}-10 \mathrm{pm})$ & 14.85 cent $/ \mathrm{kWh}$ & $9 \mathrm{INR} / \mathrm{kWh}$ \\
\hline Peak Period (PP) & $(2 \mathrm{pm}-8 \mathrm{pm})$ & 40.04 cent $/ \mathrm{kWh}$ & $10 \mathrm{INR} / \mathrm{kWh}$ \\
\hline
\end{tabular}

Table 3: Assumed Pricing Intervals for India

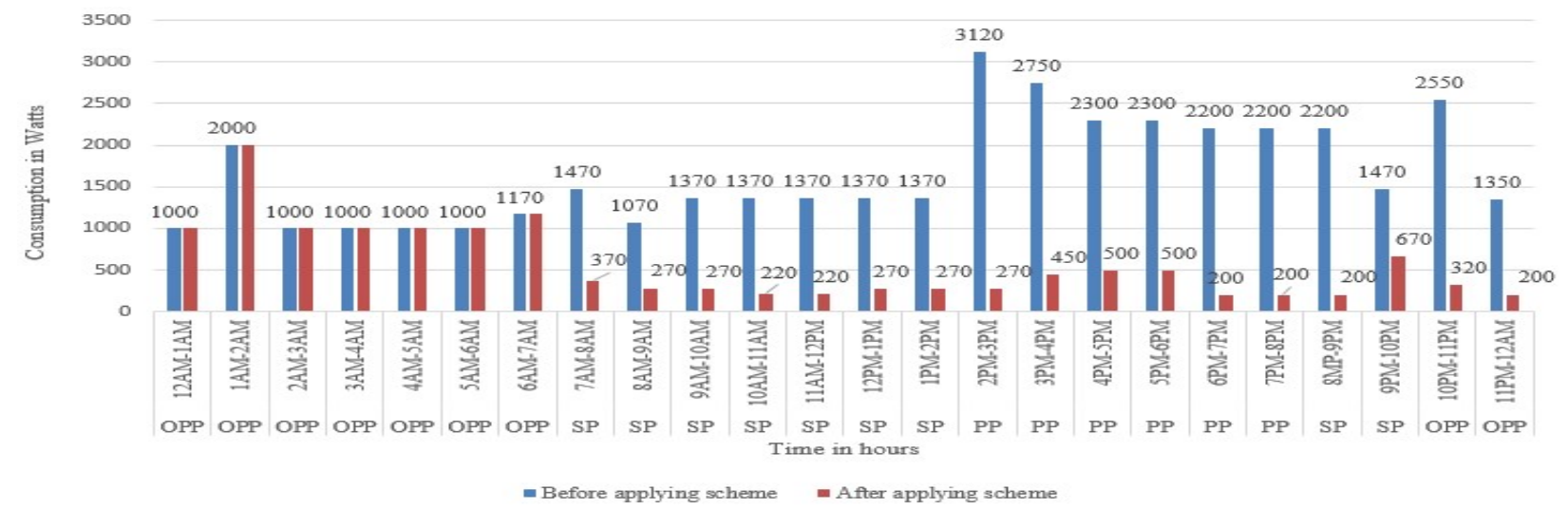

Figure 2: Load Demand Curve Before and After Applying Scheduling

The integration of all four parameters for proposed system is based on the following logic: 1) A pre decided schedule based on the real time tariff and load priority of the customer embedded in the controller. Accordingly, the information about the operating condition of different load is communicated to customer via GSM. However, it has an also facility for the customer to control this load from remote location by sending SMS. 2) Assuming that a set of devices are supposed to remain on during a particular duration of time as per schedule. 3) As per the proposed scheme, this load will be supplied by RE sources which is installed at rooftop if it is sufficient to do so. Otherwise, the remaining amount of power will be supplied by grid. If the energy generation is excess, then it will return back to grid. Because of the real time tariff the consumer has a provision to decide the load based on the tariff of grid and work in the direction of reduction of electricity bill.

\section{Results and Discussion}

A. Hardware Implementation:

The proposed scheme for development of the smart home energy management system is implemented by using locally available renewable sources. i.e. The solar panel and wind turbine generator in harmony with the grid power supply. Fig. 3. Shows the hardware implementation of smart home energy management system (SHEMS).

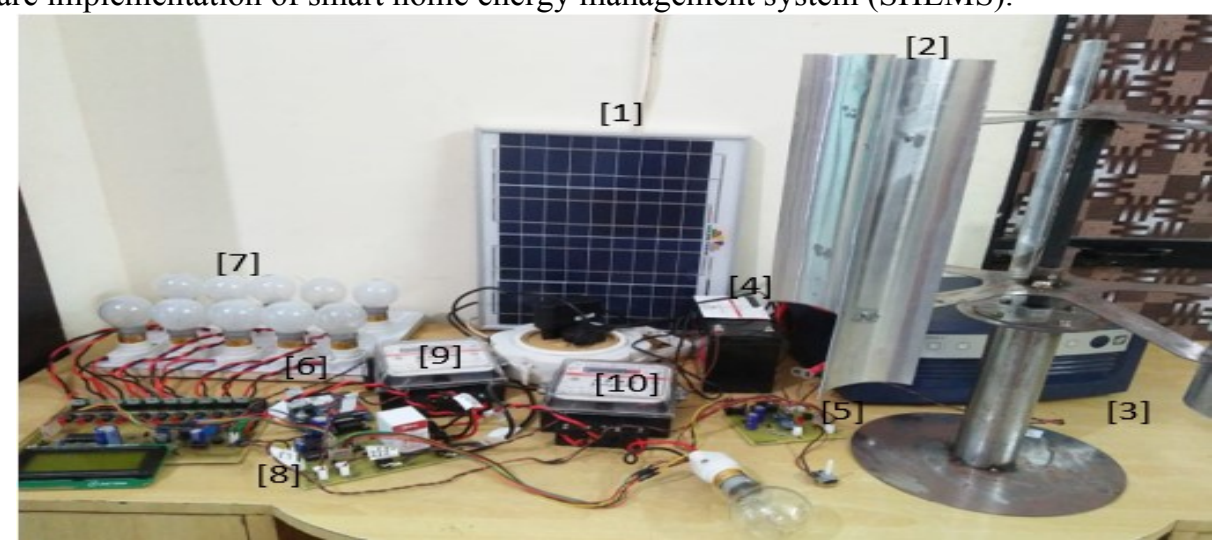

Figure 3: Experimental Setup of SHEMS 
[1] Solar Panel [2] Wind turbine generator [3] Inverter

[7] Load bank [8] Microcontroller

[9] Energy meter

[4] Battery
[6] GSM [10] Net energy meter

The battery can be charged from solar cell whenever the sun is available, from wind turbine generator whenever wind is available and from power grid during the off peak period if needed. This battery is used to source household loads using an inverter.

However, this inverter power is limited in quantity due to limited power from the renewable sources and thus cannot completely replace the grid power supply to fulfill household needs. So to optimize power requirements, load scheduling is carried out for different time slots of complete 24 hours.

GSM modem has been used for communication between the system and the user. The user gets registered into the system by calling into the SIM card number of the GSM modem. After that, the user can control the household devices. For demonstration purpose, 10 lighting loads are connected as a residential load which represents light, fan, charger, radio, tv, washing machine, refrigerator, oven, geyser, ac. The system is able to send the details on SMS like mode of operation, power usage, the cost of energy, credits if generated after every hour. ATmega family based micro-controller has been used to control and execute the functions. The flowchart for the proposed system is shown in the Fig. 4. The algorithm is explained with following steps:

Step-1: User sets load scheduling according to preference and convenience for 24 hours of time interval.

Step-2: These 24 hours are divided in three-mode of intervals: Off-Peak period (OPP), Shoulder period (SP) \& Peak period (PP).

Step-3: During PP: If battery voltage $\left(V_{b a t}\right)$ is greater than threshold value, then scheduled load will run on battery, but if $V_{b a t}$ is less than threshold value, then scheduled load will run on the grid supply.

Step-4: During SP: If $V_{b a t}$ is greater than threshold value, then scheduled load will run on battery; still $V_{b a t}$ is more than set value then net meter load will turn on. If $V_{b a t}$ is less than threshold value, then scheduled load will run on the grid supply.

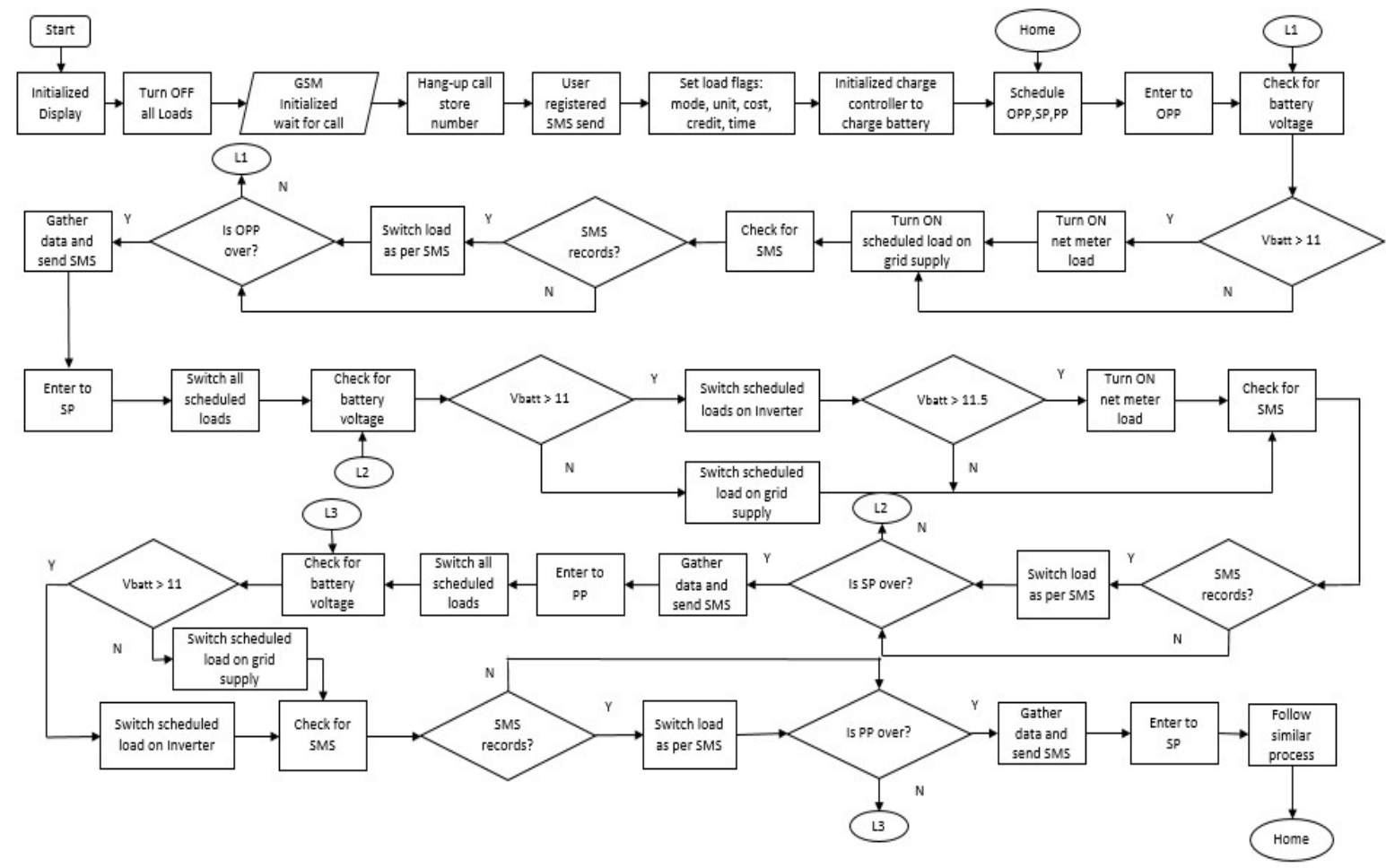

Figure 4: Flow Chart of Proposed SHEMS

Step-5: During OPP: If $V_{b a t}$ is greater than threshold value, then net meter load will run on battery and scheduled load on the grid supply. But if $V_{b a t}$ is less than threshold value, net meter load will be off and scheduled load will run on the grid supply.

Step-6: The system will send a SMS to the user about the mode of operation, power usage, cost of energy, credits if generated after every hour.

Step-7: During any interval, if the consumer wants to turn ON or OFF any device then by sending SMS, user can do so.

B. Testing: 
In this study, the assumed pricing model for India is shown in Table 3. The system was run for two different load consumption behaviors mentioned in section 2. Figs. 5-7 show a time scaled simulation for house consumption before and after applying the proposed system to the controlled load bank. In Fig. 5, the blue bars show real time unit consumption before applying the load scheduling, while the red bars show unit consumption after applying the load scheduling via SMS.

It is observed that after applying load scheduling and the real time tariff, the number of unit consumption during the peak period is reduced, so the cost of electricity will also reduce.

Fig. 6 shows the cost of unit's consumption before and after applying scheme where in both the cases real time tariff is exist. Blue line shows the cost of unit's consumption without load scheduling and red line shows the cost of unit's consumption after applying the load scheduling. It is clear from Fig. 6 that there is a reduction in the consumer bill by $34.81 \%$ and saving by $65.18 \%$. Fig. 7 shows credits earned before and after applying the scheme where excess energy left after serving the load can be feed to grid.

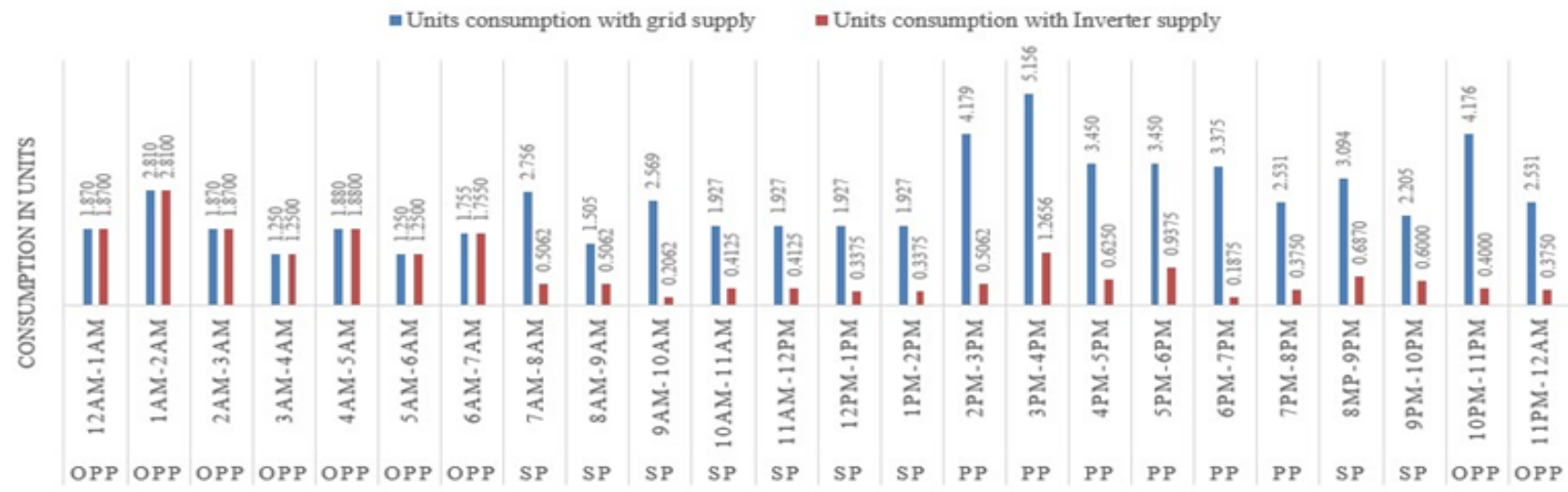

Figure 5: Unit Consumption Before and After Applying Proposed SHEMS

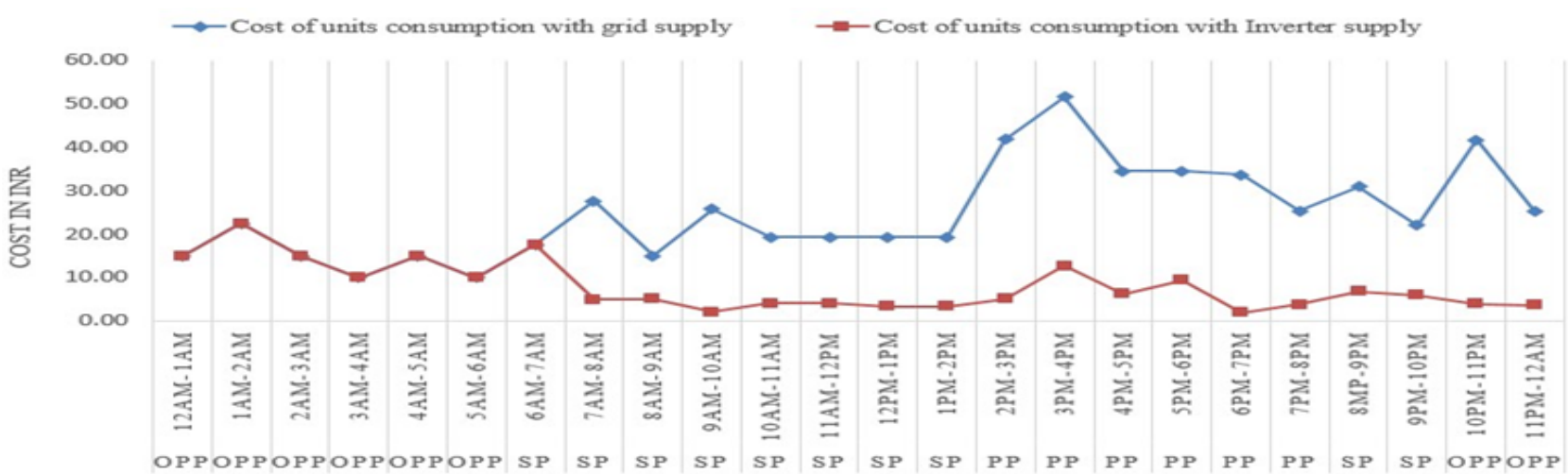

TIME IN HRS

Figure 6: Cost of Unit Consumption Before and After Applying Proposed SHEMS

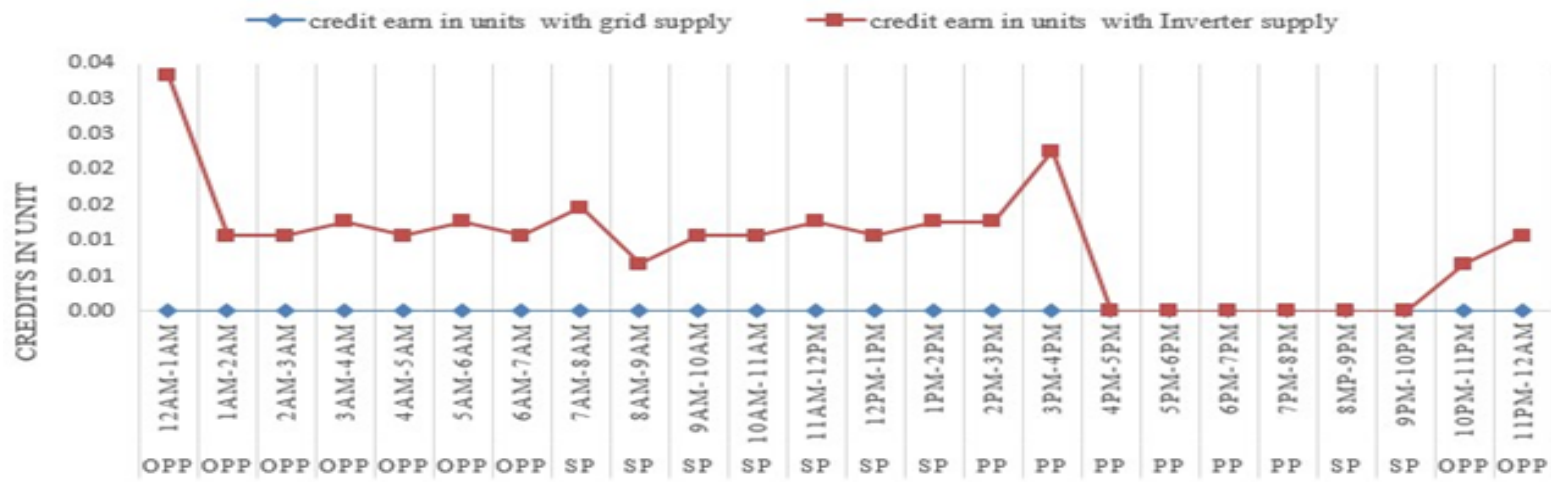

TIME IN HOURS

Figure 7: Credit Earn Before and After Applying Proposed SHEMS 


\section{Conclusion}

This paper proposes a scheme of development of SHEMS for Indian residential consumers, which integrates RE sources, load scheduling, net metering and a real time tariff. A hardware for the home energy management system with GSM communication module has been designed for 10 lighting loads. ATmega family based micro-controller has been used to control and execute the commands. Also peripherals like energy meter, current sensor, triac circuit, relay driver and LCD display have been used to measure energy flow, current flow, load power switching, power line switching and to display data respectively.

The purpose behind the development of hardware is to reduce electricity bill of residential customers in India by offering dynamic pricing, load scheduling, RE sources and net metering. The proposed scheme shows the reduction in the consumer bill by $34.81 \%$ and saving by $65.18 \%$. Also, during off peak hours and shoulder hours, primarily battery will run scheduled load and secondarily will feed to the grid to earn the credits.

\section{Acknowledgement}

Authors are grateful to the Management and Dr. B. K. Mishra, Principal, Dr. Sandhya Save, H.O.D. Electronics of Thakur College of Engineering and Technology, Mumbai, India for their support. Also grateful to Dr. Sangeeta Mishra, friends and family members, who have supported us along the way.

\section{References}

[1] P. Chavali, Y. Peng, and A. Nehorai, "Distributed Algorithm of Appliance Scheduling for Home Energy Management System”, IEEE Transaction on Smart Grid, vol. 5, no. 1, pp. 282-290, 2014.

[2] Z. Liu, W. Li and X. Liu, "Optimal Scheduling Algorithm for Residential Energy Consumption Considering WindPhotovoltaic Power and the Electricity Price of Purchase/Selling Electricity", International Journal of Smart Home, vol. 10 , no. 11 , pp. $25-38,2016$.

[3] T. Zhang, P. Liu and Z. Ju, "The Design of the Household Solar Power Generation System and its Economic Evaluation", International Journal of Smart Home, vol. 10, no. 7, pp. 29-38, 2016.

[4] World-consumption-statistics, 2017 https://yearbook.enerdata.net/total-energy/world-consumption-statistics.html. [accessed on 18.05.2018].

[5] World-energy-production,2017 https://yearbook.enerdata.net/total-energy/world-energy-production.html. [accessed on 20.05.2018].

[6] Renewable-in-electricity-production-share, 2017. https://yearbook.enerdata.net/renewables/renewable-in-electricityproduction-share.html. [accessed on 20.05.2018].

[7] Wind-solar-share-electricity-production, 2017. https://yearbook.enerdata.net/renewables/wind-solar-share-electricityproduction.html. [accessed on 22.05.2018].

[8] Electricity-domestic-consumption-data, 2017. https://yearbook.enerdata.net/electricity/electricity-domesticconsumption-data.html. [accessed on 22.05.2018].

[9] Central Electricity Authority of India, Installed Generation Capacity Report, 2018. [accessed on 11/08/2018].

[10] Ministry of New and Renewable Energy, Government of India, 2016. http://www.mnre.gov.in. [accessed on $11 / 08 / 2018]$.

[11] International Energy Agency (IEA), Market Report Series, Renewable 2017, Executive Summery. IEA Publications, 2017. [accessed on 22.05.2018].

[12] Girish G P., K. Singhania, and E. Vincent, "Solar REC Trading in India", International Journal of renewable Energy Research, vol. 7, no. 4, 2017.

[13] Nandkishor Kinhekar, Narayana Prasad Padhy, Hari Om Gupta, "Demand Side Management for Residential Consumers", IEEE conference on Power \& Energy Society General Meeting, 2013.

[14] N. Kinhekar, N. Padhy, F. Li and Hari Om Gupta, "Utility Oriented Demand Side Management using Smart AC and Micro DC Grid Coorporative", IEEE conference on Power \& Energy Society General Meeting, 2016.

[15]X. Chen, T. Wei, "Uncertainty-Aware household appliance Scheduling considering dynamic electricity pricing in smart Home," IEEE transaction on Smart Grid, vol. 4, No. 2, pp. 932- 941, June 2013.

[16] L. P. Qian, Y. Zhang, J. Huang, and Y. Wu, "Demand Response Management via Real-time Electricity Price Control in Smart Grids", IEEE Journal on Selected Areas in Communications, Vol. 31, No. 7, July 2013.

[17] http://greencleanguide.com/top-five-states-in-india-with-highest-wind-electricity-generation. [accessed on 4/08/10].

[18] A. R. Al-Ali, Ayman El-Hag, M. Bahadiri, M. Harbaji, Y. Ali El Haj, "Smart Home Renewable Energy Management System”, ICSGCE 2011, Energy Procedia 12, pp.120-126, Chengdu, China, 27-30 September 2011. 